\title{
Distribution characteristics of unmanaged cat colonies over a 20 year period in Auckland, New Zealand
}

\author{
Glenn D. Aguilar*, Mark J. Farnworth \\ Animal Welfare and Biodiversity Research Group, Department of Natural Sciences, Unitec Institute of Technology, Auckland, New Zealand
}

\section{Keywords:}

Animal welfare

Cat

Colony

GIS

Hotspot analysis

Population management

New Zealand

\begin{abstract}
A B S T R A C T
Cat colony records for the period 1991 to 2011 were used to determine spatial characteristics and relationships between cat colony density, human population, social conditions and the physical environment. Results show a positive correlation between cat colonies, population density, social indicators and the types of land where they are located. A temporal increase in the density of cat colonies is noticeable in areas where they are frequently reported, supporting the hypothesis that cat colonies are a persistent feature of Auckland's urban landscape. Complementing an earlier paper on stray cats, this paper seeks to provide information to support the implementation of management measures to mitigate both social and animal welfare concerns.
\end{abstract}

(c) 2012 Elsevier Ltd. All rights reserved.

\section{Introduction}

As urbanization increases so too does the complexity of human-animal interactions within the urban landscape. To date the causes and impacts of such interactions are little understood (Magle, Hunt, Vernon, \& Crooks, 2012). However, urbanization has been shown to increase populations of some animals, especially those closely associated with human colonization (van Rensburg, Peacock, \& Robertson, 2009) to the detriment of overall biodiversity (Shochat et al., 2010).

Domestic cats (Felis catus) are an intrinsic component of contemporary human society kept for both functional (e.g. rodent control) and relational (e.g. companionship) reasons (Bernstein, 2005). As human populations become more urbanized, the cat population is increasing, in part due to the perception they are easier to care for than dogs (Gelson, 2010), but also due to an increase in anthropogenic food sources (Liberg, 1980). Cats are New Zealand's most popular companion animal (pet) with an estimated number in excess of 1.4 million and a household ownership level of 48\% (MacKay, 2011). In Auckland, New Zealand sterilization rates for owned cats are high (McKay, Farnworth, \& Waran, 2009) however many cats are also free-roaming (Farnworth, Campbell, \& Adams, 2010). As for other nations (e.g. Israel: Finkler \& Terkel, 2012) there is no requirement for cats to be confined or licensed in New Zealand. In this regard the unowned cat population is

\footnotetext{
* Corresponding author. Tel.: +6498154321x7019.

E-mail addresses: gaguilar@unitec.ac.nz (G.D. Aguilar), mfarnworth@ unitec.ac.nz (M.J. Farnworth).
}

relatively persistent because, as shown in other nations, it is likely to be supported by abandonment of unwanted cats and reproduction with the unsterilised owned cat population (Bradshaw, Horsfield, Allen, \& Robertson, 1999; Robertson, 2008). Typically, cat colonies can be considered to be "A group of three or more sexually mature animals living and feeding in close proximity to one another" (Slater, 2005). Colonies are often semi-owned (Toukhsati, Bennett, \& Coleman, 2007) or managed by interested parties (Tennent, Downs, \& Bodasing, 2009) however, a substantial number of colonies are not managed. When resolving unmanaged cat colonies reported by the public, available information including the age, number and sex of the animals, is often limited. Therefore, for the purposes of this research, we propose that an unmanaged colony should be considered as: "Three or more individual cats and/ or kittens reported to be permanently resident in a given location and with no discernible owner or caregiver". Therefore they can be considered as distinct from the stray cat population reported in an earlier paper (Aguilar \& Farnworth, 2012).

Unmanaged colonies persist due to a combination of factors including suitable environments, the presence of reliable food sources (Hansen, 1994; Morgan et al., 2009) and a reproductively viable owned cat population (Slater et al., 2008a). These conditions are consistently present in urban areas and therefore population growth is relatively unhindered. The welfare of unmanaged cat colonies is of concern in that they may only receive ad hoc care, are often in poor condition and have a lower survival rate (Robertson, 2008). In Melbourne Australia, health conditions of cats from colonies were found to be generally poorer than non-colony cats. They displayed significantly increased incidences of cat flu, elevated flea burdens and evident scarring (Marston \& Bennett, 
2009). In addition cat colonies provide a potential source of zoonotic diseases (e.g. Toxoplasmosis: Dabritz \& Conrad, 2010). Animal health related concerns include the possibility of endemically infected colonies providing generators of new strains for domestic cat pathogens such as Feline calicivirus (FCV) (Radford et al., 2003) and Feline Immunodeficiency Virus (FIV) (Spada et al., 2012). FIV prevalence showed a significant increase over a three year period in a cat colony in Rio de Janeiro, Brazil. (Mendes-de-Almeida, 2007). Free-roaming and feral cats also provide a significant source of public nuisance (Patronek, 1998). Colonies of cats may be particularly problematic when they occur within the proximity of native wildlife reserves although urban colonies still have a significant impact of local fauna (Baker, Bentley, Ansell, \& Harris, 2005; Lepczyk, Mertig, \& Liu, 2003). Flux (2007) reported that in seventeen years a single pet cat in New Zealand killed 558 individual animals, of which 223 were birds, 54 of which were native. New Zealand's indigenous avifauna is poorly adapted to introduced mammalian predators. As a result the impact of cats is not only potentially negative but may be devastating even in low numbers (e.g. King, 1984). All of these factors result in a need for environmental protection and cat population management. Perceived nuisance increases negative public perceptions of cats leading to a marked reduction in public sympathies which, in turn, may increase support for less humane or lethal management processes (Farnworth, Campbell, \& Adams, 2011).

Effective and humane resolution for unwanted and unmanaged cat colonies may function to improve the welfare and public image of cats in general. Most commonly, Trap-Neuter-Release/Return (TNR) is utilized and has been shown to work if all available females are sterilized on a biannual basis (Mendes-de-Almeida et al., 2011). However research indicates that public support for TNR is less strong in New Zealand (Farnworth et al., 2011) when compared to other countries (Natoli et al., 2006). A recent review of TNR has also concluded that many of the claims made in its support are either not broadly applicable, demonstrably false or unquantifiable (Longcore, Rich, \& Sullivan, 2009). Whether or not this is the case, there is little evidence that on-going TNR programs result in extinction of colonies (Slater et al., 2008b). To compound matters further the cat is also a registered pest in some regions of New Zealand (Farnworth, Dye, \& Keown, 2010). Therefore, returning unowned animals to unmanaged colonies may be questionable on legal as well as ethical and welfare grounds. Resolution of the problems associated with a persistent stray cat population may be best served by removal and rehoming of socialized adult cats and actively socialized kittens (Casey \& Bradshaw, 2008). In the event that the animal is unable to be rehomed, and is not from a managed colony, humane euthanasia may be the most suitable alternative.

Stray cats have been shown to be strongly associated with population density and social deprivation indices in Auckland New Zealand (Aguilar \& Farnworth, 2012). This is yet to be established for cat colonies which may represent more persistent features of the urban landscape. Therefore the determination of social and ecological space and cat colony characteristics are critical. It will allow identification, visualization and prioritization of areas of concern in terms of both animal welfare and wildlife protection. The availability of data from 1995 to 2011 on unmanaged cat colonies within the Auckland region provided an opportunity to establish a geographic information system (GIS) for building such an approach. As these colonies were actively resolved, the data provide a valuable insight into the numbers of such cats, especially as individuals often underestimate the colony's size, even if closely associated with it (Jones \& Downs, 2011). It will also allow examination of the distribution characteristics of cat colonies and the social and environmental factors that may be relevant.
We hypothesize that cat colonies are strongly associated with human habitation and may correlate with social characteristics represented by indices such as the New Zealand Deprivation Index or NZDI (Salmond, Crampton, \& Atkinson, 2007). Based on the 2006 census the parameters are referred to as "dimensions of deprivation" and include as variables (in order of decreasing weight), home ownership, employment status, age, qualifications (New Zealand term for the level of education), living space, access to communication and access to a car (Salmond, Crampton, King, \& Waldegrave, 2006). In addition we propose that colony numbers may be increasing, becoming more persistent in some urban areas and expanding their range into others. The latter hypothesis is considered in light of colony proximity to areas of significant ecological value.

\section{Methods}

Data collected over a period of 20 years (1991-2011) by the Lonely Miaow Association Incorporated were processed for GIS analyses. The data consisted of spreadsheets recording public reports of cat colonies, with addresses, date of response and the number of cats or kittens rescued. Addresses were geocoded using publicly available geocoding engines to provide point features for spatial analyses. In some instances, only areas and not addresses were provided. In this case, the coordinates defaulted to the coordinates of the area returned by geocoding resource, either the centroid of the official census area unit or the centroid of the mesh block, which is the smallest census area in the New Zealand census system. The geocoded point features were then spatially joined with the official census area units of the Auckland region. This allowed the measurement of cat colony density per unit area $\left(\mathrm{km}^{2}\right)$ that provided a dependent variable for the subsequent analyses.

Distribution characteristics of cat colony densities were mapped for the entire period. To show whether a temporal increase in density was evident, the densities were aggregated for four time intervals (1991-1999, 2000-2003, 2004-2007 and 2008-2011). This also allowed determination of changes in distribution of cat colonies over the 20 year period. The aggregation was also necessary to determine whether specific areas consistently showed higher or lower densities for the time intervals.

Data on human population density were sourced from the official census statistics. The New Zealand Land Use Map of 2008 was used to provide information on the physical environment.

A hotspot analysis of cat colony distribution was then undertaken using the Getis Ord Gi*. The "hotspots" refer to an area with relatively higher concentrations of cat colonies as compared to surrounding areas, whereas "coldspots" indicate the opposite. The major diagnostic value for determining the hotspots are the $z$ scores and $p$-values of the analysis (Getis \& Ord, 1992; Ord \& Getis, $1995,2001)$. The $\mathrm{Gi}^{*}$ statistic returned for the feature in the dataset is a $z$-score. For statistically significant positive $z$-scores, the larger $z$-score represents more intense clustering of high values (hotspots). For statistically significant negative $z$-scores the smaller the $z$-score the more intense the clustering of low values (coldspots). For this analysis, $p$-value was set at $p<0.05$. Related applications of spatial clustering using the $\mathrm{Gi}^{*}$ statistic include ecology and species distributions (Dennis, Aspinall, \& Gordon, 2002; Rissler \& Smith, 2010; Shaker, Crăciun, \& Grădinaru, 2010), diseases (Kao, Getis, Brodine, \& Burns, 2010) and historical analysis (Zhang, Wong, So, \& Lin, 2011).

While the Getis Ord $\mathrm{Gi}^{*}$ statistic is useful for identifying hotspots and coldspots, specific areas that exhibit statistically significant spatial outliers can only be identified by the Anselin's Local Moran's I approach (Anselin, 1995). Anselin's Local Moran's I measuring similarities or dissimilarities in the parameter's values with the 
surrounding area units. Inverse weighted distance squared and the Euclidean distance measurement was employed as options in the analysis. Groupings of positive $I$ values with significant $z$-scores showed evidence of clustering while groupings of negative spatial autocorrelation indices provides an argument for a lack of clustering. A minimum of six significant positive indices in close proximity were used as evidence of clustering, similar to the work of Schuurman, Peters, and Oliver (2009). To further characterize results of Anselin's Local Moran's I, areas with statistically significant indices ( $p$-value $<0.05$ ) are classified using local and global mean cat colony densities (local mean refers to the average cat colony density using the area's neighbourhood): HH for areas with local means higher than the global mean; LL for areas with local means lower than the global mean; HL for areas with values higher than the local mean and; LH for areas with values lower than the local mean. (Mitchell, 2005)

The kernel density of cat colony locations was determined to show the relative density distribution over the area. The kernel density calculation produces a surface raster that fits a smoothly curved surface over each point. A value of a raster cells is determined by a quadratic kernel function that uses the location of each cat colony as an input coordinate (Silverman, 1986). Overlaying the kernel density surface over layers of population density and land use types provided an initial visualization of possible relationships between the cat colonies, the human population and the physical environment.

The Ordinary Least Squares (OLS) tool was used as a means to determine the relationship between cat colony density and the explanatory variables including population density, a measure of socioeconomic conditions represented by the New Zealand Deprivation Index of 2006 (NZDI) (Salmond et al., 2006) and the physical environment using the New Zealand land use map of 2008. As a global diagnostic, the OLS as implemented in ArcMap provides several statistical measures useful for evaluating the results of the analysis. This work follows the approach in Mitchell (2005) as well as the OLS component of the work of Năpăruş and Kuntner (2012). In case where the model determined by OLS is indicated as misspecified by the diagnostic tools included, local regression using the Geographically Weighted Regression (GWR) is utilized. GWR has the advantage of providing the local $r^{2}$, local standard errors, and measures of significance that provide a description of spatial influences between variables (Fotheringham, Brunsdon, \& Charlton, 2002; Legendre, 1993).

\section{Results}

A total of 1930 sites were visited following public reports. These reports resulted in a total of 5679 individual cats being rescued or removed. For the period 1991-2011, the mean number of cats per colony was 4.42 . The data were divided into specific time periods for convenience in displaying temporal variation. The time intervals were for three years, with the exception of 1991-1999 because of the small number of early records. An increase in the number of cat colonies and the number of cats or kittens as shown in the record is evident (Table 1). Such an increase may be a result of the enhanced awareness of the public and improved efficiencies in reporting and data collection.

Table 1

Summary of cat colony data for Auckland from 1991 to 2011.

\begin{tabular}{|c|c|c|c|c|}
\hline \multirow[t]{2}{*}{ Number } & \multicolumn{4}{|l|}{ Year } \\
\hline & 1991-1999 & 2000-2003 & 2004-2007 & 2008-2011 \\
\hline Reported cat colonies & 131 & 569 & 536 & 694 \\
\hline Rescued cats/kittens & 144 & 915 & 2218 & 2402 \\
\hline
\end{tabular}

Cat colonies were primarily concentrated within, or adjacent to, the former Auckland City boundaries with secondary clustering by the adjacent western area of the former Waitakere City. These areas are the most urbanized with the highest population density, commercial activity and industrial zones. The Land use map of 2008 shows the different area types. The Auckland central area consists mainly of settlements surrounded by grassland and forest areas that coincide with lesser population density and at first glance, also lesser cat colony density (Fig. 1).

Overall $75 \%$ of all reported colonies were found within residential zones, $10 \%$ within commercial zones and 12\% across hospitals, schools and restaurants with the remainder in countryside or beach locations. When aggregated for the entire period the higher cat colony densities (colonies per square kilometre calculated per unit census area) were also found to be located within the Auckland City boundaries with the Eastern most suburbs showing the greatest densities. Over the specified time intervals, it can be seen that the cat colonies show a spreading characteristic or increase in the areas reporting the presence of cat colonies throughout the region. Also evident is the consistent increase in the densities at areas where they are persistent (Fig. 2).

The results of the Getis Ord $\mathrm{Gi}^{*}$ analysis show definite hotspots and coldspots of cat colonies densities in the study area. Consistent with the earlier observation of greater densities in the urbanized areas of Auckland, the hotspots (characterized by red in Fig. 3 in the web version) indicate significant clustering of high values in the central areas while areas north and south are significant coldspots (characterized by blue). When the different time interval periods were plotted, results show a focusing of the hotspot or narrowing in the central area. The hotspot results support the previous density distribution providing significant proof of the concentration of cats in the central Auckland City areas.

Anselin's local Moran analysis showed the local area characteristics in the form of cluster/outlier types (COType). Results show that the $\mathrm{HH}$ types occur within the hotspot identified by the Getis Ord $\mathrm{Gi}^{*}$ statistic. Areas that show the $\mathrm{HH}$ types appear to be consistent throughout the time defined time intervals (Fig. 4). A COType of LH is shown near the eastern boundary of Auckland City which is near Waitakere ranges. This is of concern since this is an area of high biodiversity and conservation in this area involves the control of mammalian predators.

Results of the ordinary least squares analysis for determining the correlation between cat colony and population density show that the resulting $t$-statistic $(7.206 ; p<0.001)$ indicates that the coefficient is significantly different from zero, which in turn signals that population densities are correlated with cat colony densities. Both the Joint F-Statistic (51.926; $p<0.001)$ and Joint Wald Statistic (53.082; $p<0.001)$ indicate that the model is robust. The JanqueBerra (4405.863; $p<0.001$ ) statistic shows significant $p$-values requiring the determination of Moran's $I$ for checking spatial autocorrelation. Results of Moran's $I(-0.004 ; p=0.838)$ indicate that spatial autocorrelation is not present in the relationship between cat colony density and population density. This is indicative of some degree of consistency in the relationships between population density and cat colony density in both data and geographic dimensions.

When the kernel density was generated and combined with the land use map of the area, the surface plot showed the concentration of the colonies within the area classified as Settlements (Fig. 5). With most of the higher values for cat colony densities obviously found within Settlement areas, there was no need for OLS or other statistical tool to establish a relationship.

In terms of the socioeconomic conditions represented by the NZDI of 2006, the $t$-statistic $(5.646 ; p<0.001)$ also indicates a relationship where the coefficient is significant and a positive 


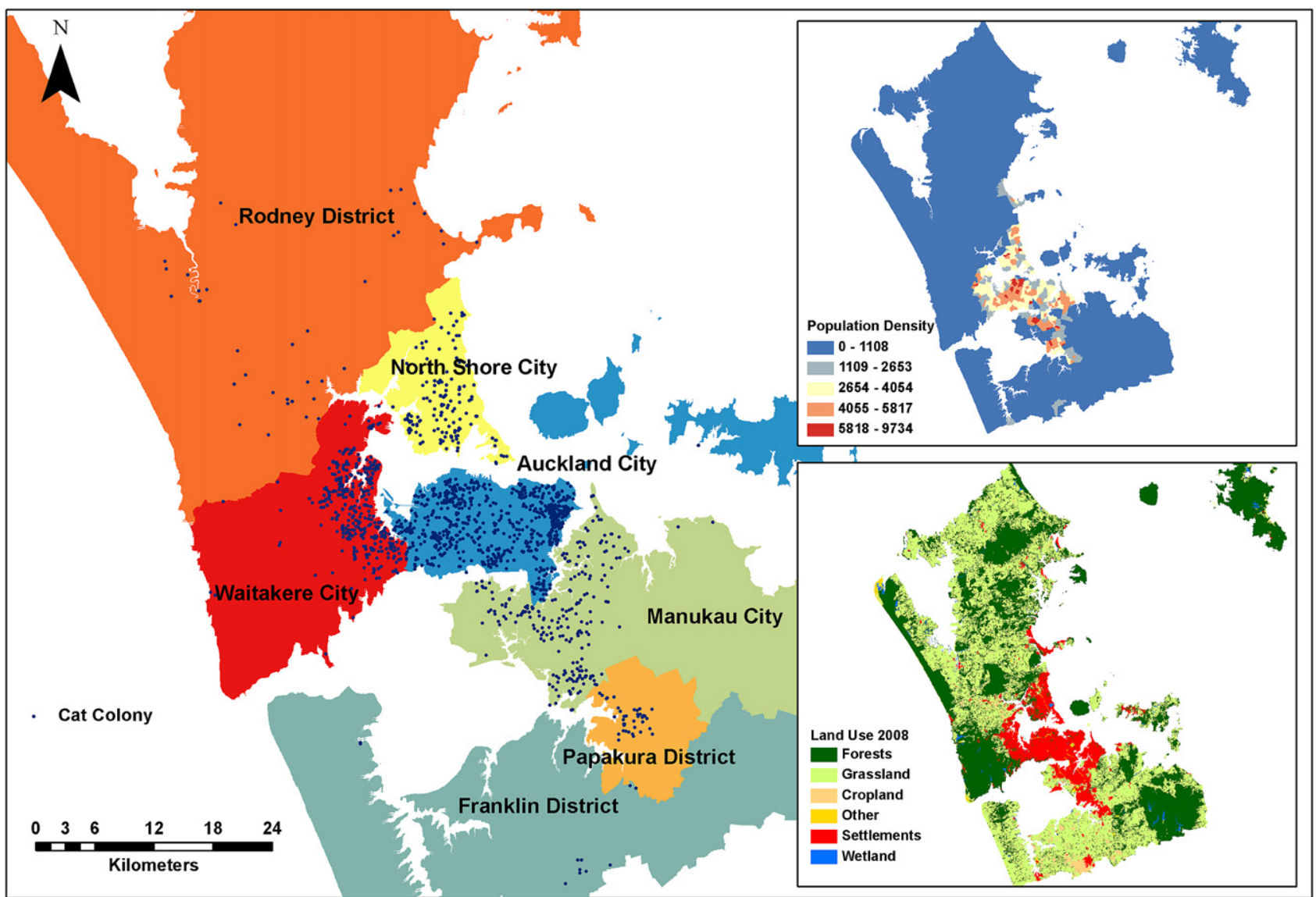

Fig. 1. Cat colony locations from 1991 to 2011, population density of Auckland and the land use classification of 2008 (clockwise starting from the large map).

correlation exists between the cat colony densities and NZDI scores. Both the joint- $F(31.880 ; p<0.001)$ and joint-Wald (15.776; $p<0.001)$ indicate the robustness of the model but the Koenker (BP) $(12.618 ; p<0.001)$ is significant, requiring the use of robust $t$ statistic $(2.615 ; p=0.010)$ values for evaluation. The robust $t$ statistic indicates that the coefficient is still significant. The value of the Koenker (BP) statistic $(1.086 ; p=0.483)$ is not significant and shows evidence of the absence of non-stationarity. The Janque-Bera $(18,342 ; p<0.001)$ statistic is significant requiring the use Moran's test on the residuals to test for spatial autocorrelation. The value of Moran's $I(-0.000 ; p=0.044)$ is significant, indicating spatial autocorrelation although the $p$-value is quite close to the cutoff level of significance. This latter result prompted the use of local regression using GWR to determine if a better model could be derived. Results of GWR showed an AICc of 88868.937 which is less than the OLS AICc of 89070.819 . With a difference of more than 3 the GWR provides a better description of the relationship between the levels of deprivation and cat colony density. Low values of $r^{2}$ shows a weak correlation between cat colony density and the NZDI indicating only a small measure of dependency between these variables. This is reflected in the local $r^{2}$ map of GWR results where the highest values are shown in a relatively small area east of the central city district which is also the location of the highest cat colony densities (Fig. 6).

\section{Discussion}

The availability of long term data with location information provides a significant contribution towards understanding the dynamics of unmanaged cat colonies. There appears to be significant evidence that they are becoming a persistent feature of the Auckland landscape. This is even more important when their spatial distribution is directly related to the human population density, the physical characteristics of the environment and socioeconomic conditions. For organizations such as animal welfare charities, the consistent collection of data with geographic co-ordinates provides a valuable contribution towards a better understanding. This includes more informed decision making around humane management of previously unmanaged cat colonies and the development of policies to address such decisions. In turn, these may lead to advances in free-roaming cat welfare as well as improvements in targeted community education and human health and well-being.

The data collected demonstrated greater numbers of reports in later years. This may have been affected by several factors which include: increased awareness of the charity and the services it offers; advances in telecommunications technology and facilities; increases in the number of cat colonies; increased perception of, or heightened concern for, animal welfare. This research was focused only on the available data, hence any assumptions of conclusive or deterministic trends such as cat colony growth or increased ease of reporting are, at this stage, provisional and should be subjected to future research.

As reporting comes directly from the public the correlation between colony density and human population density may simply reflect a greater likelihood of report. However other research shows that outside dense human habitation the cat population is substantially lower (e.g. 0.7 cats $/ \mathrm{km}^{2}$ Kangaroo 


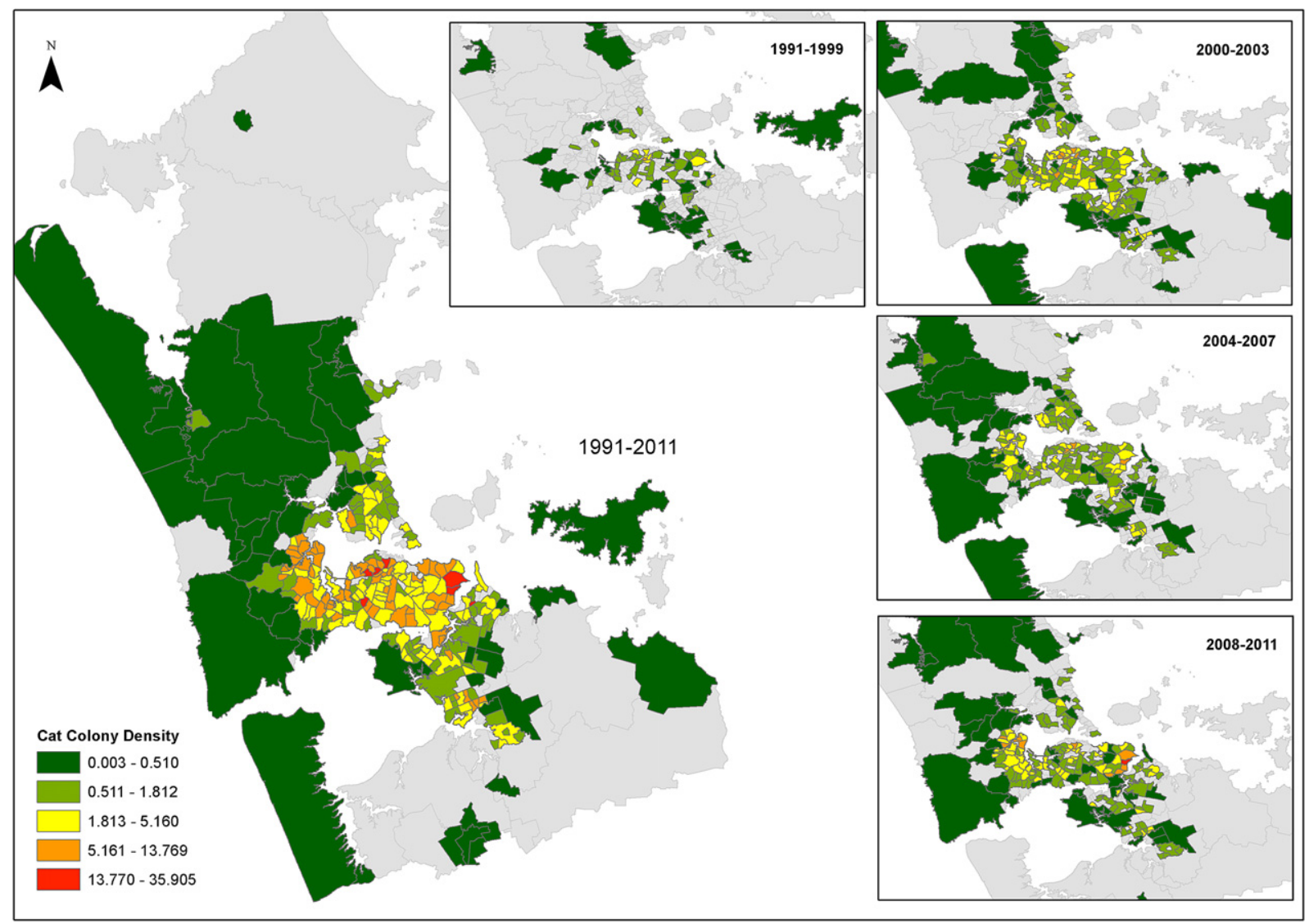

Fig. 2. Density of cat colonies in Auckland from 1991 to 2011 with densities at different time periods (1991-1999, 2000-2003, 2004-2007 and 2008-2011).

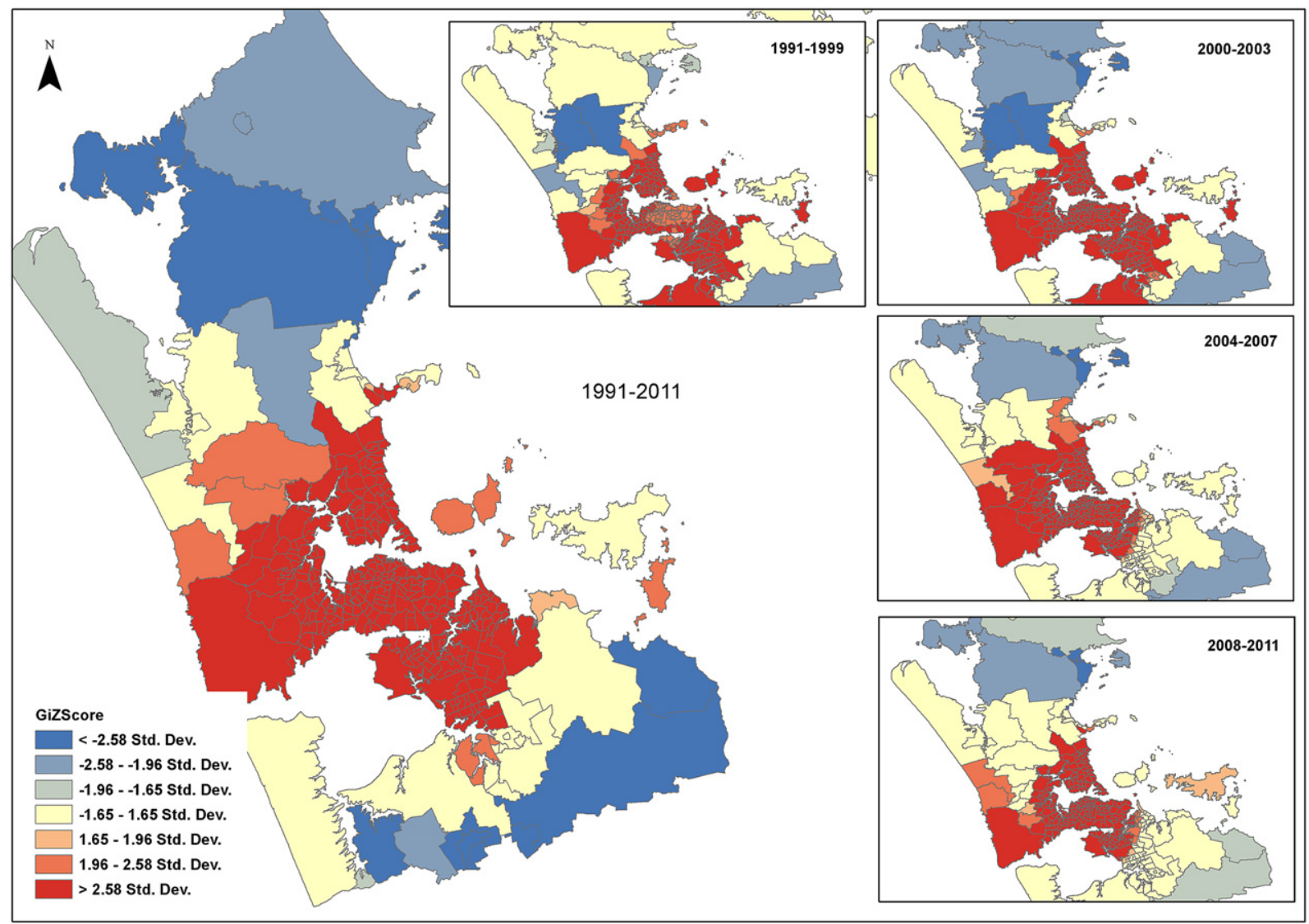

Fig. 3. Hotspots of cat colonies over the period 1991-2011. 


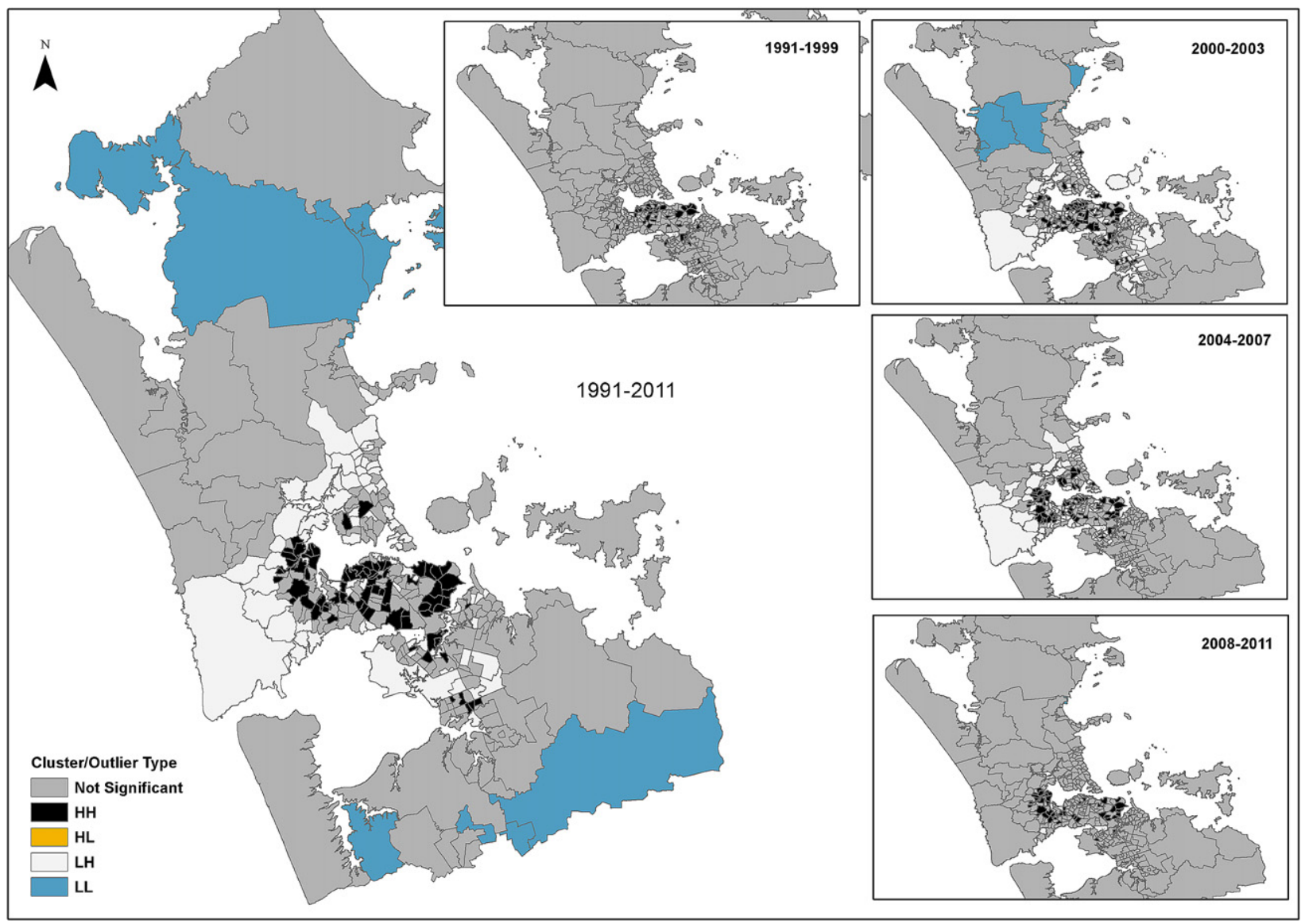

Fig. 4. Anselin's local Moran I COType map results.

Island, Australia; Bengsen, Butler, \& Masters, 2011) when compared to inhabited areas (e.g. 223 cats $/ \mathrm{km}^{2}$ Dunedin, New Zealand; van Heezik, Smyth, Adams, \& Gordon, 2010). Although our correlations between the cat and human populations agree with field surveys outside New Zealand (Ferreira, Leitão, da Santos-Reis, \& Revilla, 2011) further work, involving monitoring colony sites is necessary to validate and improve the results of this work in local and national contexts.
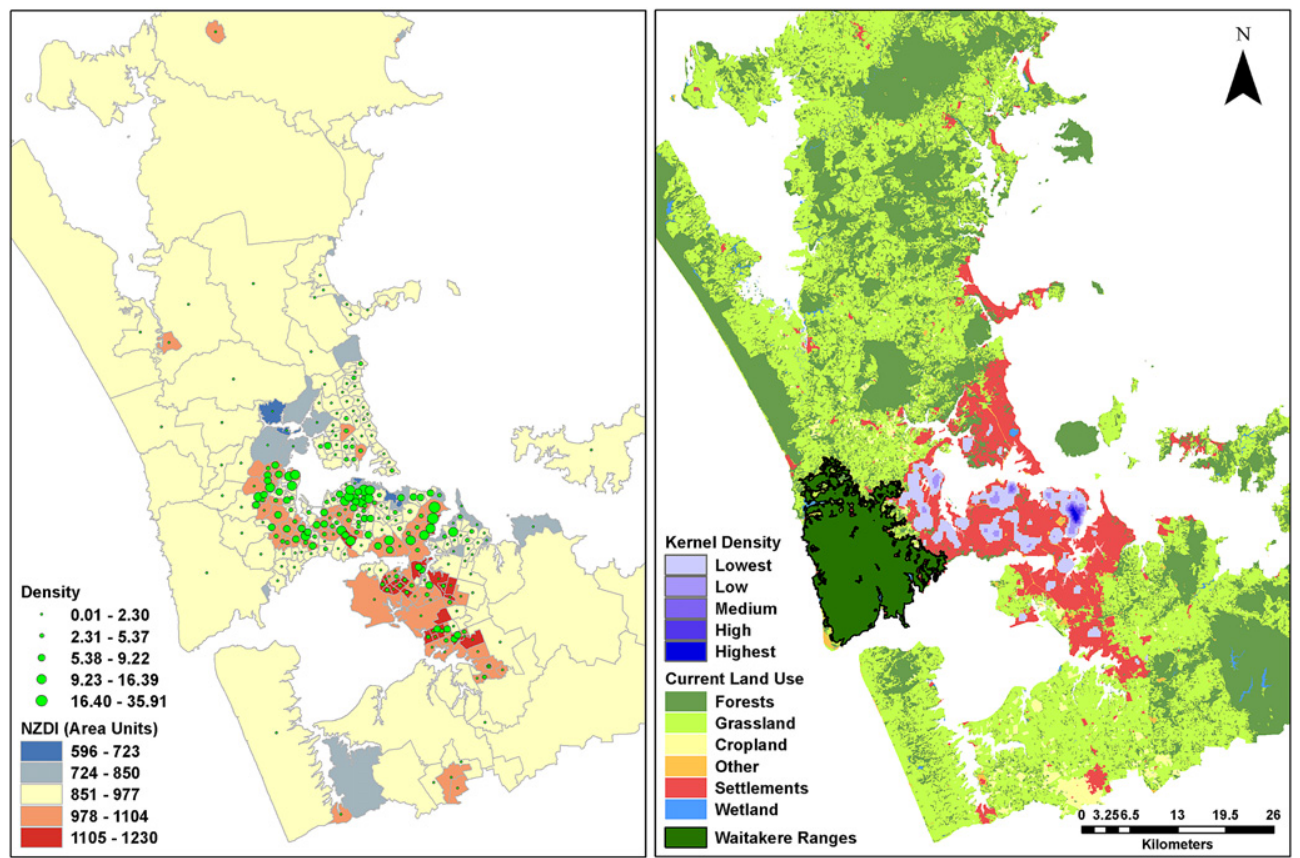

Fig. 5. Plots of cat colony density with the NZDI 2006 and cat colony kernel density with land use types. 


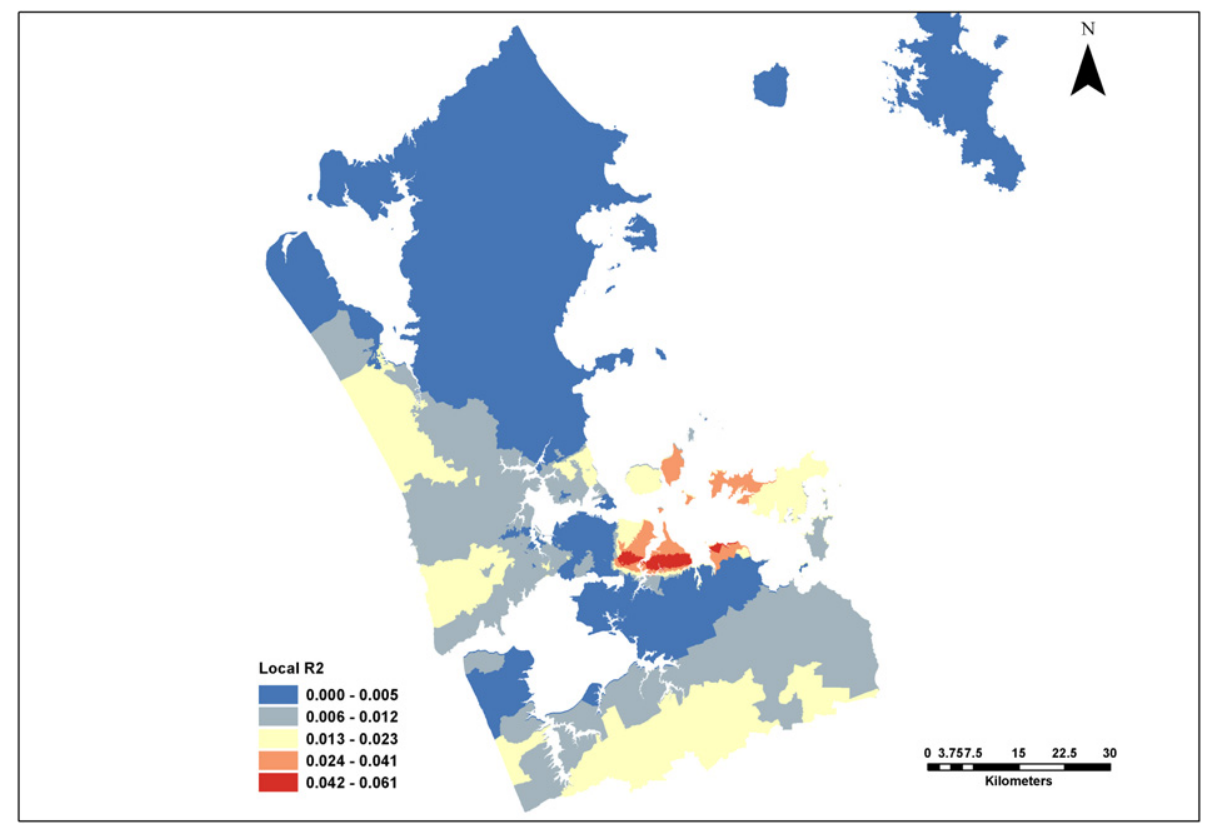

Fig. 6. GWR results with local $r^{2}$.

Irrespective of issues around reporting of the data sets, exploration shows persistent cat colony presence consistent with population density and land use types. We can therefore conclude that cat colonies are currently a persistent feature of Auckland's landscape, intrinsically linked to the human population density and settlement areas. As for Aguilar and Farnworth (2012), some evidence points to linkages with the conditions represented by NZDI which may affect persistence of cat colonies. However, the weak statistical relationships found present a future challenge that may involve dissecting or disaggregating the elements that make up the index to discover more consistent relationships between individual NZDI indicators and the persistence of unmanaged cat colonies. It is important to note that the data used in Aguilar and Farnworth (2012) and this research come from different sources. It may be that the location and geographic influence of the two charitable organizations has some impact on where cats are reported and found. A combined exploration of the two data sets may therefore be warranted.

While there is no evidence of the high density areas spreading or expanding ( $\mathrm{HH}$ areas), the increasing trend of densities in the same areas point to conditions that allow increases in cat colony densities. Of particular interest in terms of animal welfare and biodiversity is the presence of an LH area near western areas of Auckland (Waitakere). Fereirra et al. (2011) suggests that home ranges are significant enough to allow regular incursion to nearby areas of conservation. Urban fringe exclusion zones have been estimated to be $1.2 \mathrm{~km}$ to prevent incursion of cats into sensitive areas (Metsers, Seddon, \& van Heezik, 2010). With the Waitakere ranges regional park undergoing ecological restoration and pest mammal control efforts, the presence of nearby cat colonies and the trend of increasing densities provide a realistic threat to this area and on-going efforts to protect native fauna in managed areas such as 'Ark in the Park' that is found within the Waitakere Ranges (see Fig. 5).

\section{Conclusions}

This research identifies several areas of high and persistent unmanaged cat colony density. Results of hotspot and cluster analysis showed distinct clustering of cat colonies in areas with higher population density. This provides an opportunity to focus interventions to address the issue especially since limited resources are available. Education campaigns and information awareness efforts in these neighbourhoods, which are relatively higher density residential areas with a high deprivation index, may be a more efficient utilization of public and private resources as compared to a blanket or area wide approach. Currently, unlike some areas of Australia, New Zealand does not have stringent controls in place to manage the cat population. In Australia, these measures include curfews and containment of companion cats (Toukhsati, Young, Bennett, \& Coleman, 2012). As New Zealanders have a generally ambivalent attitude towards cats (Farnworth et al., 2011), it may be pertinent to begin dialogue similar to that of Lilith, Calver, Styles, and Garkaklis (2006) which focused on public support for cat population management options in Australia. For Auckland, discussion could be centred on the concerns of the public in areas identified as having high densities of unowned cats. An early proactive approach to finding solutions may allow open discussion of humane alternatives such as compulsory registration and identification of cats, TNR and exclusion zones around areas of significant ecological value. Effective population control is likely to require an integrated approach across a number of private and public entities. The increasing density and persistence of cat colonies suggests current strategies may not be working.

\section{Acknowledgements}

The Authors would like to thank the volunteers of the Lonely Miaow Association Incorporated and, in particular, Peter Dormon for his assistance with this work.

\section{References}

Aguilar, G. D., \& Farnworth, M. J. (2012). Stray cats in Auckland, New Zealand: discovering geographic information for exploratory spatial analysis. Applied Geography, 34, 230-238.

Anselin, L. (1995). Local indicators of spatial association-LISA. Geographical Analysis, 27(2), 93-115.

Baker, P. J., Bentley, A. J., Ansell, R. J., \& Harris, S. (2005). Impact of predation by domestic cats (Felis catus) in an urban area. Mammal Review, 35, 302-312.

Bengsen, A., Butler, J., \& Masters, P. (2011). Estimating and indexing feral cat population abundances using camera traps. Wildlife Research, 38, 732-739. 
Bernstein, P. (2005). The human-cat relationship. In I. Rochlitz (Ed.), The welfare of cats (pp. 47-89). Dordrecht: Springer.

Bradshaw, J. W. S., Horsfield, G. F., Allen, J. A., \& Robinson, I. H. (1999). Feral cats: their role in the population dynamics of Felis catus. Applied Animal Behaviour Science, 65, 273-283.

Casey, R. A., \& Bradshaw, J. W. S. (2008). The effects of additional socialisation for kittens in a rescue centre on their behaviour and suitability as a pet. Applied Animal Behaviour Science, 114, 196-205.

Dabritz, H. A., \& Conrad, P. A. (2010). Cats and toxoplasma: implications for public health. Zoonoses and Public Health, 57, 34-52.

Dennis, P., Aspinall, R. J., \& Gordon, I. J. (2002). Spatial distribution of upland beetles in relation to landform, vegetation and grazing management. Basic and Applied Ecology, 3(2), 183-193.

Farnworth, M. J., Campbell, J., \& Adams, N. J. (2010). Public awareness in New Zealand of animal welfare legislation relating to cats. New Zealand Veterinary Journal, 58, 213-217.

Farnworth, M. J., Campbell, J., \& Adams, N. J. (2011). What's in a name? Perceptions of stray and feral cat welfare and control in Aotearoa New Zealand. Journal of Applied Animal Welfare Science, 14, 59-74.

Farnworth, M. J., Dye, N. G., \& Keown, N. (2010). The legal status of cats in New Zealand: a perspective on the welfare of companion, stray and feral domestic cats (Felis catus). Journal of Applied Animal Welfare Science, 13, 180-188.

Ferreira, J. P., Leitão, I., Santos-Reis, M., \& Revilla, E. (2011). Human-related factors regulate the spatial ecology of domestic cats in sensitive areas for conservation. PLOS ONE, 6, Art. no. e25970.

Finkler, H., \& Terkel, J. (2012). The contribution of cat owners' attitudes and behaviours to the free-roaming cat overpopulation in Tel Aviv, Israel. Preventive Veterinary Medicine, 104, 125-135.

Flux, J. E. C. (2007). Seventeen years of predation by one suburban cat in New Zealand. New Zealand Journal of Zoology, 34, 289-296.

Fotheringham, S. A., Brunsdon, C., \& Charlton, M. (2002). Geographically weighted regression: The analysis of spatially varying relationships. Chicester: Wiley.

Gelson, G. (2010). Domestic cat: future challenge for the control of urban rabies? Pesquisa Veterinária Brasileira, 30, 186-189.

Getis, A., \& Ord, J. K. (1992). The analysis of spatial association by use of distance statistics. Geographical Analysis, 24, 189-206.

Hansen, C. M. (1994). Movements and predation activity of feral and domestic cats (Felis catus) on Banks Peninsula. Lincoln University Digital Dissertation.

van Heezik, Y., Smyth, A., Adams, A., \& Gordon, J. (2010). Do domestic cats impose an unsustainable harvest on urban bird populations? Biological Conservation, $143,121-130$.

Jones, A. L., \& Downs, C. T. (2011). Managing feral cats on a university's campuses: how many are there and is sterilization having an effect? Journal of Applied Animal Welfare Science, 14, 304-320.

Kao, A. S., Getis, A., Brodine, S., \& Burns, J. C. (2010). Spatial and temporal clustering of Kawasaki syndrome cases. Journal of Pediatrics Infectious Diseases, 27(11) 981-985.

King, C. (1984). Immigrant killers: Introduced predators and the conservation of birds in New Zealand. Oxford: Oxford University Press.

Legendre, P. (1993). Spatial autocorrelation: trouble or new paradigm? Ecology, 74, 1659-1673.

Lepczyk, C. A., Mertig, A. G., \& Liu, J. (2003). Landowners and cat predation across rural-to-urban landscapes. Biological Conservation, 115, 191-201.

Liberg, O. (1980). Spacing patterns in a population of rural free roaming domestic cats. Oikos, 198, 336-349.

Lilith, M., Calver, M., Styles, I., \& Garkaklis, M. (2006). Protecting wildlife from predation by owned domestic cats: application of a precautionary approach to the acceptability of proposed cat regulations. Austral Ecology, 31, 176-189.

Longcore, T., Rich, C., \& Sullivan, L. M. (2009). Critical assessment of claims regarding management of feral cats by trap-neuter-return. Conservation Biology, 23, 887-894

MacKay, J., \& NZCAC (New Zealand Companion Animal Council Incorporated) (2011). Companion animals in New Zealand.

Magle, S. B., Hunt, V. M., Vernon, M., \& Crooks, K. R. (2012). Urban wildlife research past, present, and future. Biological Conservation, 155, 23-32.

Marston, L. C., \& Bennett, P. C. (2009). Admissions of cats to animal welfare shelters in Melbourne, Australia. Journal of Applied Animal Welfare Science, 12(3), 189-213.

McKay, S. A., Farnworth, M. J., \& Waran, N. K. (2009). Current attitudes towards, and incidence of, sterilization of cats and dogs by owners in Auckland, New Zealand. Journal of Applied Animal Welfare Science, 12, 331-334.

Mendes-de-Almeida, F., Labarthe, N., Guerrero, J., Faria, M. C. F., Branco, A. S. Pereira, C. D., et al. (2007). Follow-up of the health conditions of an urban colony of free-roaming cats (Felis catus Linnaeus, 1758) in the city of Rio de Janeiro, Brazil. Veterinary Parasitology, 147(1-2), 9-15.
Mendes-de-Almeida, F., Remy, G. L., Gershony, L. C., Rodrigues, D. P., Chame, M., \& Labarthe, N. V. (2011). Reduction of feral cat (Felis catus Linnaeus, 1758) colony size following hysterectomy of adult female cats. Journal of Feline Medicine and Surgery, 13, 436-440.

Metsers, E. M., Seddon, P. J., \& van Heezik, Y. M. (2010). Cat-exclusion zones in rural and urban-fringe landscapes: how large do they have to be? Wildlife Research, $37,47-56$

Mitchell, A. (2005). The ESRI guide to GIS analysisIn Spatial measurements and statistics, Vol. 2. Redlands, CA: ESRI Press.

Morgan, S. A., Hansen, C. M., Ross, J. G., Hickling, G. J., Ogilvie, S. C., \& Paterson, A. M. (2009). Urban cat (Felis catus) movement and predation activity associated with a wetland reserve in New Zealand. Wildlife Research, 36(7), 574-580.

Natoli, E., Maragliano, L., Cariola, G., Faini, A., Bonanni, R., Cafazzo, S., et al. (2006) Management of feral domestic cats in the urban environment of Rome (Italy). Preventive Veterinary Medicine, 77, 180-185.

Năpărus, M., \& Kuntner, M. (2012). A GIS model predicting potential distributions of a lineage: a test case on hermit spiders (Nephilidae: Nephilengys). PLOS ONE, 7(1), Art. no. e30047.

Ord, J. K., \& Getis, A. (1995). Local spatial autocorrelation statistics: distributional issues and an application. Geographical Analysis, 27, 286-306.

Ord, J. K., \& Getis, A. (2001). Testing for local spatial autocorrelation in the presence of global autocorrelation. Journal of Regional Science, 41, 411-432.

Patronek, G. J. (1998). Free-roaming and feral cats - their impact on wildlife and human beings. Journal of the American Veterinary Medical Association, 212, 1394-1398

Radford, A. D., Dawson, S., Ryvar, R., Coyne, K., Johnson, D. R., Cox, M. B., et al. (2003). High genetic diversity of the immunodominant region of the feline calicivirus capsid gene in endemically infected cat colonies. Virus Genes, 27(2), 145-155.

van Rensburg, B. J., Peacock, D. S., \& Robertson, M. P. (2009). Biotic homogenization and alien bird species along an urban gradient in South Africa. Landscape and Urban Planning, 92(3-4), 233-241.

Rissler, L. J., \& Smith, W. H. (2010). Mapping amphibian contact zones and phylogeographical break hotspots across the United States. Molecular Ecology, 19(24), 5404-5416.

Robertson, S. A. (2008). A review of feral cat control. Journal of Feline Medicine and Surgery, 10, 366-375.

Salmond, C., Crampton, P., \& Atkinson, J. (2007). NZDep 2006 index of deprivation user's manual. Wellington: Dept. of Public Health, University of Otago.

Salmond, C., Crampton, P., King, P., \& Waldegrave, C. (2006). NZiDep: a New Zealand index of socioeconomic deprivation for individuals. Social Science $\mathcal{E}$ ' Medicine, 62(6), 1474-1485

Schuurman, N., Peters, P. A., \& Oliver, L. N. (2009). Are obesity and physical activity clustered? A spatial analysis linked to residential density. Epidemiology, 17, 2202-2209.

Shaker, R. R., Crăciun, A. I., \& Grădinaru, I. (2010). Relating land cover and urban patterns to aquatic ecological integrity. Geographia Technica, 9(1), 76-90.

Shochat, E., Lerman, S. B., Anderies, J. M., Warren, P. S., Faeth, S. H., \& Nilon, C. H. (2010). Invasion, competition, and biodiversity loss in urban ecosystems. BioScience, 60(3), 199-208.

Silverman, B. W. (1986). Density estimation for statistics and data analysis. New York: Chapman and Hall.

Slater, M. L. (2005). The welfare of feral cats. In I. Rochlitz (Ed.), The welfare of cats (pp. 141-176). Dordrecht: Springer.

Slater, M. R. Di Nardo, A., Pediconi, O., Dalla Villa, P., Candeloro, L., Alessandrini, B., et al. (2008a). Cat and dog ownership and management patterns in Central Italy. Preventive Veterinary Medicine, 85, 267-294.

Slater, M. R., Di Nardo, A., Pediconi, O., Dalla Villa, P., Candeloro, L., Alessandrini, B. et al. (2008b). Free-roaming dogs and cats in central Italy: public perceptions of the problem. Preventive Veterinary Medicine, 84, 27-47.

Spada, E., Proverbio, D., Della Pepa, A., Perego, R., Baggiani, L., Bagnagatti De Giorgi, G., et al. (2012). Seroprevalence of feline immunodeficiency virus, feline leukaemia virus and Toxoplasma gondii in stray cat colonies in northern Italy and correlation with clinical and laboratory data. Journal of Feline Medicine and Surgery, 14(6), 369-377.

Tennent, J., Downs, C. T., \& Bodasing, M. (2009). Management recommendations for feral cat (Felis catus) populations within an urban conservancy in KwaZuluNatal, South Africa. South African Journal of Wildlife Research, 39, 137-142.

Toukhsati, S. R., Bennett, P. C. \& Coleman, G. J. (2007). Behaviours and attitudes towards semi-owned cats. Anthrozoös, 20, 131-142.

Toukhsati, S. R., Young, E., Bennett, P. C., \& Coleman, G. J. (2012). Wandering cats: attitudes and behaviours towards cat containment in Australia. Anthrozoös, 25 , 61-74.

Zhang, P., Wong, D. W., So, B. K. L., \& Lin, H. (2011). An exploratory spatial analysis of western medical services in Republican Beijing. Applied Geography, 32, 556-565. 